\title{
ION ASSOCIATION. III. THE EFFECT OF SULFATE INFUSION ON CALCIUM EXCRETION $* \dagger$
}

\author{
By MACKENZIE WALSER AND ANN A. BROWDER $\ddagger$ \\ (From The Department of Pharmacology and Experimental Therapeutics, The Johns Hopkins \\ Unicersity School of Medicine, Baltimore, Md.)
}

(Submitted for publication February 23, 1959; accepted April 23, 1959)

In the course of a study directed towards replacing extracellular chloride with sulfate in dogs, it was noted that sulfate infusion led to a considerable increase in the urinary excretion of calcium and signs of calcium deficiency $(1,2)$. The formation of a complex between calcium and sulfate was considered as a possible explanation of this observation, since it is well known that organic anions which complex calcium, including citrate (3) and ethylenediaminetetracetic acid (EDTA) (4), also augment calcium excretion. However, the nature of the association between calcium and sulfate in aqueous solution differs fundamentally from the covalent complexes formed with citrate and EDTA. It is believed that electrostatic forces alone are responsible for the apparently incomplete dissociation of calcium sulfate $(5,6)$. The physiological properties of this type of complex have not been previously studied.

This paper is one in a series directed towards this general problem. In the first paper (7) it was shown that the addition of multivalent anions (sulfate, phosphate or ferrocyanide) to serum led to an increased amount of complexed calcium in serum ultrafiltrate, determined by the difference between free calcium ion concentration (measured by the purpurate method) and total ultrafiltrable calcium. The results were consistent with the interpretation that calcium, when electrostatically paired with multivalent anions, does not combine with purpurate. In the second paper it was shown that calcium ions, when associated with

\footnotetext{
* This work was supported in part by a grant from the American Cancer Society for Institutional Cancer Research, and by a grant from the National Science Foundation (NSF-G2113).

$\dagger$ Presented in part before the American Society for Clinical Investigation, May, 1958.

\$Work performed during tenure of a National Science Foundation student fellowship. Present address: Cornell Medical Division, Bellevue Hospital, New York, N. Y.
}

sulfate, thiosulfate or dibasic phosphate, are not effective in sustaining cardiac contraction in the frog heart preparation (8).

In the present report it is demonstrated that urinary excretion of calcium is augmented by sulfate infusion and that this effect is far greater than during comparable diuresis induced by other agents. Wolf and Ball (9) observed increased excretion of calcium, magnesium and potassium during sulfate diuresis but found similar changes during infusion of 5 per cent glucose solution. The present data indicate that the action of sulfate in promoting calcium excretion is many times greater than can be attributed to urine flow alone. The interpretation that calcium is complexed by sulfate and thereby rendered less readily reabsorbed is shown to be consistent with the observations.

\section{METHODS}

Twenty-four experiments were performed on unanesthetized female dogs, connected to a constant infusion apparatus with a catheter in the jugular vein (10). This was inserted under local anesthesia with procaine hydrochloride. An indwelling catheter was inserted in the bladder and taped to the dog's back. The bladder was emptied every 15 to 40 minutes depending upon urine flow, but was not washed out. Venous blood samples were obtained in syringes containing heparin at approximately the mid-point of each period and were placed under oil. Plasma and diluted urine samples were stored in the frozen state until analyzed. Infusions were prepared from reagent grade chemicals dissolved in redistilled water and were warmed to prevent excessive cooling of the animal. The rate of infusion was controlled by a pump. Creatinine was administered in a priming dose followed by a sustaining infusion in all of the experiments. Fifteen experiments were performed in which sulfate was infused; in six, chloride was removed during the course of the experiment in order to achieve higher concentrations of sulfate in the plasma. This was accomplished by injecting intraperitoneally a volume of warmed fluid equivalent to 8 to 12 per cent of the animal's weight. This fluid was isosmotic and contained sodium sulfate as the major solute. One and one-half to two hours later, the peritoneal cavity was drained through a size 15 
needle. The procedure was repeated as necessary to reduce the plasma chloride.

Infusion composition. The composition of the fluid employed for intravenous infusion was varied as follows: Even when relatively small amounts of sulfate were infused, the ensuing loss of calcium in the urine led to the development of hypocalcemia. Therefore, in most experiments calcium was added to the infusions either as calcium acetate or chloride. Occasionally this resulted in hypercalcemia, but these data have been omitted from the present paper. The remaining observations have been divided into two categories, those periods in which total plasma calcium was normal ( 2.25 to $2.75 \mathrm{mMoles}$ per $\mathrm{L}$., i.e., 9 to $11 \mathrm{mg}$. per cent) and those with hypocalcemia (less than 2.25 mMoles per L.)

It was observed that sulfate infusion increased the urinary excretion of magnesium. Therefore experiments were performed both with and without the addition of $\mathrm{MgSO}_{*}$ to the infusion. Hypermagnesemia was intentionally induced in some experiments, in order to counteract the symptoms of hypocalcemia. The results have been separated into periods with normal or reduced plasma magnesium $(<1.5 \mathrm{mMoles}$ per L. $)$ and those with hypermagnesemia $(>1.5 \mathrm{mMoles}$ per $\mathrm{L}$.), since magnesium is known to affect calcium excretion under certain conditions (11).

Potassium depletion also develops during infusion of large amounts of sodium sulfate (1). Therefore, $\mathrm{K}_{2} \mathrm{SO}_{4}$ was added to the infusions in amounts sufficient to offset urinary losses and to maintain plasma potassium concentrations within the normal range.

At moderate rates of infusion $(<10 \mathrm{ml}$. per minute) plasma bicarbonate and $\mathrm{pH}$ were not appreciably altered by infusions of mixtures of $\mathrm{Na}_{2} \mathrm{SO}_{4}, \mathrm{CaCl}_{2}, \mathrm{~K}_{2} \mathrm{SO}_{4}$ and $\mathrm{MgSO}_{4}$. In the six experiments in which high plasma sulfate concentrations were produced by peritoneal dialysis, the development of moderate acidosis necessitated the administration of extra alkali, given as sodium acetate in the infusion.

The sodium concentration of isosmotic sodium sulfate solution is approximately $240 \mathrm{mEq}$. per L.; a sodium sul. fate solution containing $140 \mathrm{mEq}$. of sodium per L. is markedly hypotonic ( $c a .192 \mathrm{mOsm}$. per L.). Therefore, it is not possible to achieve a high plasma concentration of sulfate without inducing either hypernatremia or hypotonicity, unless a nonelectrolyte is also given. Rather than introduce the added complication of a nonelectrolyte such as mannitol, which would also act as an osmotic diuretic, we chose to compromise between hypernatremia and hypotonicity, permitting some degree of both. The infusions therefore contained sodium at concentrations of 160 to $200 \mathrm{mEq}$. per L., but were slightly hypotonic. The range of infusion concentrations studied for each of the other ions was as follows: potassium, 18 to $20 \mathrm{mEq}$. per L.; magnesium, 0 to $16 \mathrm{mMoles}$ per L.; calcium, 0 to 5 mMoles per L.; sulfate, 95 to $120 \mathrm{mMoles}$ per L.; acetate, 0 to $7 \mathrm{mMoles}$ per L.; chloride, 0 to $10 \mathrm{mEq}$. per $\mathrm{L}$. The effect of these infusions upon acid-base balance is of course unrelated to the $\mathrm{pH}$ of the solution infused but depends instead upon the buffer content, and upon secondary adjustments within the animal. The only buffer ion infused was acetate, which was included in four experiments at high plasma sulfate levels. When infused at less than $10 \mathrm{ml}$. per minute, the following solution was found to induce the least changes in the bicarbonate, potassium, calcium and magnesium concentrations of plasma: $\mathrm{Na}_{2} \mathrm{SO}_{4}, 0.09 \mathrm{M} ; \mathrm{K}_{2} \mathrm{SO}_{4}, 0.008 \mathrm{M}$; $\mathrm{MgSO}_{4}, 0.003 \mathrm{M} ; \mathrm{CaCl}_{2}, 0.003 \mathrm{M}$. It follows that this solution corresponds closely to the composition of the urine during prolonged sulfate diuresis.

In nine control experiments, either $0.16 \mathrm{M} \mathrm{NaCl}, 0.16 \mathrm{M}$ $\mathrm{NaHCO}_{3}, 0.3 \mathrm{M}$ sucrose or mixtures of these solutions were infused at rates varying from 5 to $30 \mathrm{ml}$. per minute, and the clearances of calcium and creatinine were determined. Since these infusions do not cause rapid depletion of calcium, magnesium or potassium, these cations were not added to the infusions.

The analytical methods employed were as follows: potassium, internal standard flame photometry; calcium, oxalate precipitation and permanganate titration (12, $13)$; magnesium, titan yellow $(14,15)$; chloride, amperometric titration (16); sulfate, benzidine precipitation and either titration of the precipitate (17) or colorimetric analysis of benzidine $(18,19)$; creatinine, alkaline picrate method (20); and protein, biuret method (21). With the calcium, magnesium and sulfate methods, the recovery of these substances added to plasma or urine was determined in each run. The mean recovery and probable errors of each method were as follows: calcium, $103 \pm 3$ per cent; magnesium, $104 \pm 5$ per cent; sulfate, $95 \pm 6$ per cent. Sulfate did not interfere with the determination of calcium or magnesium.

Calcium clearance was calculated without correction for protein binding.

\section{RESULTS}

\section{The effect of rate of urine flow upon calcium excretion}

In the lower portion of Figure 1 are shown the changes observed in calcium excretion during diuresis induced by infusions of $\mathrm{NaCl}, \mathrm{NaHCO}_{3}$ or sucrose. In the normal dog, calcium clearance is approximately 0.4 per cent of the glomerular filtration rate $(22,23)$. During administration of $\mathrm{NaCl}, \mathrm{NaHCO}_{3}$ or sucrose, this fraction increased to a maximum of 10 per cent or approximately twentyfold. This effect, although recognized qualitatively $(9,22)$, has not been previously documented in a quantitative manner. The interpretation of the effect of any agent upon the renal excretion of calcium without taking this phenomenon into consideration is hazardous.

\section{The effect of sulfate infusion on calcium excretion}

Two representative experiments are presented in Table I. In the first experiment (Dog F.) a 


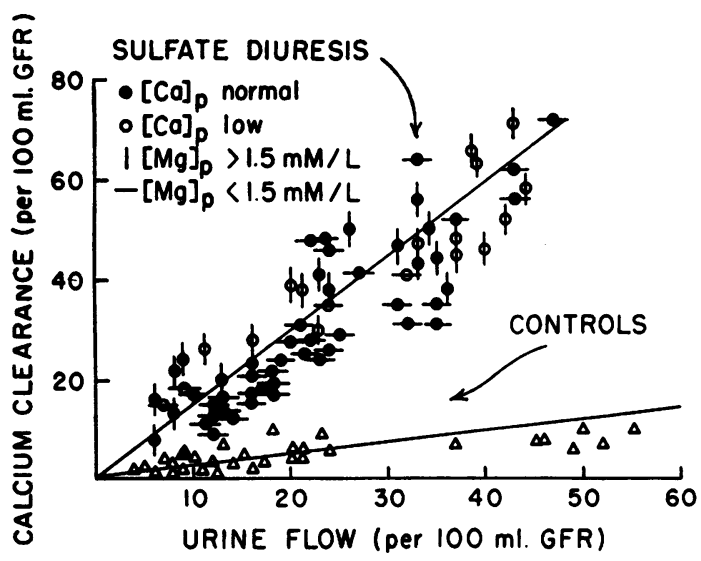

Fig. 1. Calcium Clearance as a Function of Urine Flow During Infusion of Sulfate

Control observations were obtained during infusion of $\mathrm{NaCl}, \mathrm{NaHCO}_{6}$ or sucrose.

sulfate solution containing calcium was infused for 74 minutes, at $10 \mathrm{ml}$. per minute. This resulted in a plasma sulfate concentration of $12.6 \mathrm{mMoles}$ per L., and calcium clearances of 13 and 16 per cent of filtration rate. When calcium was omitted from the infusion, plasma calcium fell to 1.8 mMoles per L. (7.2 mg. per cent). Nevertheless, the calcium clearance ratio increased, concomitant with a rise in plasma sulfate to 19 mMoles per L. The concurrence of marked hypercalcuria and hypocalcemia suggests that the latter is due to the former, and indicates that the hypercalcuric effect of sulfate is pronounced.

In the experiment in Dog L., a considerably greater plasma sulfate level was achieved by employing repeated peritoneal dialysis. The dialysis fluid contained calcium, but the intravenous infusion fluid did not. The rate of infusion was adjusted to approximate the rate of urine flow, so that extracellular fluid volume was not greatly altered (except for the fluid in the peritoneal cavity). Plasma magnesium was progressively elevated to $3.8 \mathrm{mMoles}$ per $\mathrm{L}$. in order to counteract the symptoms of hypocalcemia. Plasma calcium fell to $1.3 \mathrm{mMoles}$ per $\mathrm{L}$. (5.2 $\mathrm{mg}$. per cent) as plasma sulfate increased to greater than 44 mMoles per $\mathrm{L}$. The calcium clearance ratio increased to 0.79, a value far in excess of any previously reported. With the exception of EDTA (22), no other agent has been reported to increase the calcium clearance ratio above 0.2 . In the last period, the glomerular filtration rate fell to sub- normal levels and the experiment was discontinued.

The results of all of the experiments are presented graphically in Figure 1. Calcium clearance is plotted as a function of urine flow, both parameters having been divided by filtration rate in order to minimize variation due to the size of individual dogs. Data obtained at subnormal filtration rates have been excluded (see below). Observations obtained during diuresis with $\mathrm{NaCl}$, $\mathrm{NaHCO}_{3}$ or sucrose are shown in the lower portion of the figure, and those with sulfate in the upper portion. Most of the values of urine flow per $100 \mathrm{ml}$. GFR greater than 25 were obtained from dogs subjected to peritoneal dialysis.

At comparable urine flows, calcium clearance is several times greater during sulfate diuresis than during diuresis induced by $\mathrm{NaCl}, \mathrm{NaHCO}_{\text {: }}$ or sucrose. The concentration of calcium in the urine remained relatively constant despite the great augmentation of urine flow, and as a result the relationship between calcium clearance and urine flow is approximately linear. The slope of the line indicates that the concentration of calcium in the urine is, on the average, one and onefourth times the concentration of calcium in plasma. In the control studies with $\mathrm{NaCl}$, $\mathrm{NaHCO}_{3}$ and sucrose the ratio of urine calcium to plasma calcium concentrations averaged 0.23 .

The data presented in Figure 1 also indicate that the effect of sulfate on calcium clearance is independent of the plasma concentration of calcium. The failure of hypocalcemia to affect this relationship emphasizes the obligatory nature of this action of sulfate. Furthermore, since hypercalcuria persists despite hypocalcemia, the effects cannot be attributed to the calcium which was infused in most of the experiments. The range of plasma calcium concentrations in the hypocalcemic animals was 1.2 to 2.25 mMoles per L., averaging 1.9 mMoles per $\mathrm{L}$.

Magnesium was given in large amounts in some experiments to counteract the symptoms of hypocalcemia. It was important, therefore, to establish that the changes in calcium excretion were not the result of hypermagnesemia (range, 1.5 to 3.8 mMoles per L.). As indicated in Figure 1, the results were not significantly different in the presence of increased plasma magnesium, whether plasma calcium was normal or reduced. 
TABLE I

The development of calcium deficiency during sulfate infusion

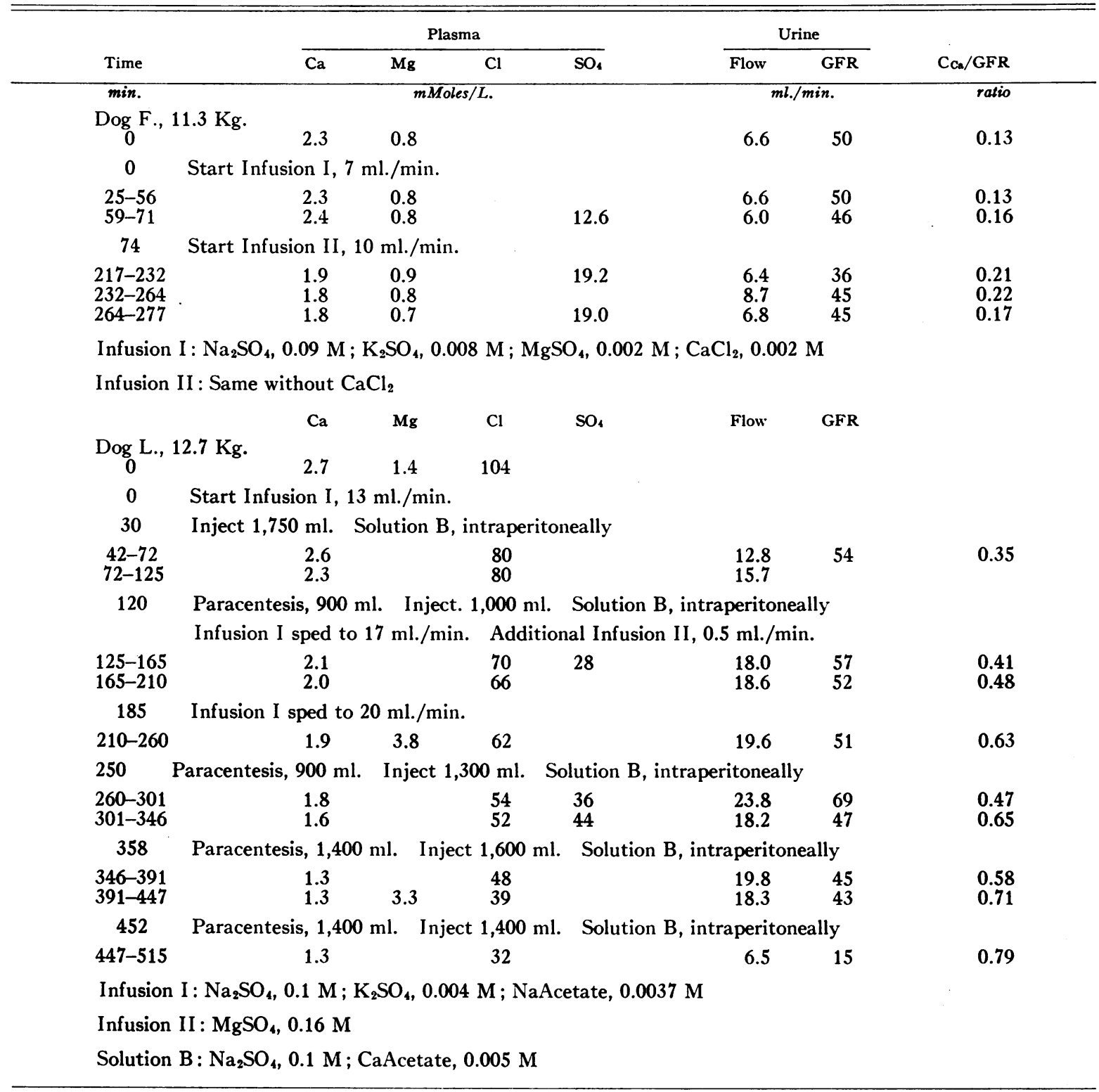

The lowest rates of sulfate infusion studied were equivalent to approximately 5 per cent of glomerular filtration rate. These infusions induced an increase in plasma sulfate from a normal value of $1 \mathrm{mMole}$ per L. (in the dog) to approximately 6 mMoles per L. As Figure 1 shows, even these observations made during mild sulfate diuresis differ considerably from those obtained with $\mathrm{NaCl}$, $\mathrm{NaHCO}_{3}$ or sucrose.

Table II, discussed below, also shows the effect of a low rate of sulfate infusion on calcium excretion. The substitution of sulfate solution for saline at $5 \mathrm{ml}$. per minute led to a fivefold increase in calcium excretion.

The effect of hyperkalemia on the calciuretic action of sulfate

In most of the experiments potassium was administered in order to maintain a normal potas- 
TABLE II

The effect of hyperkalemia on the calciuretic action of sulfate

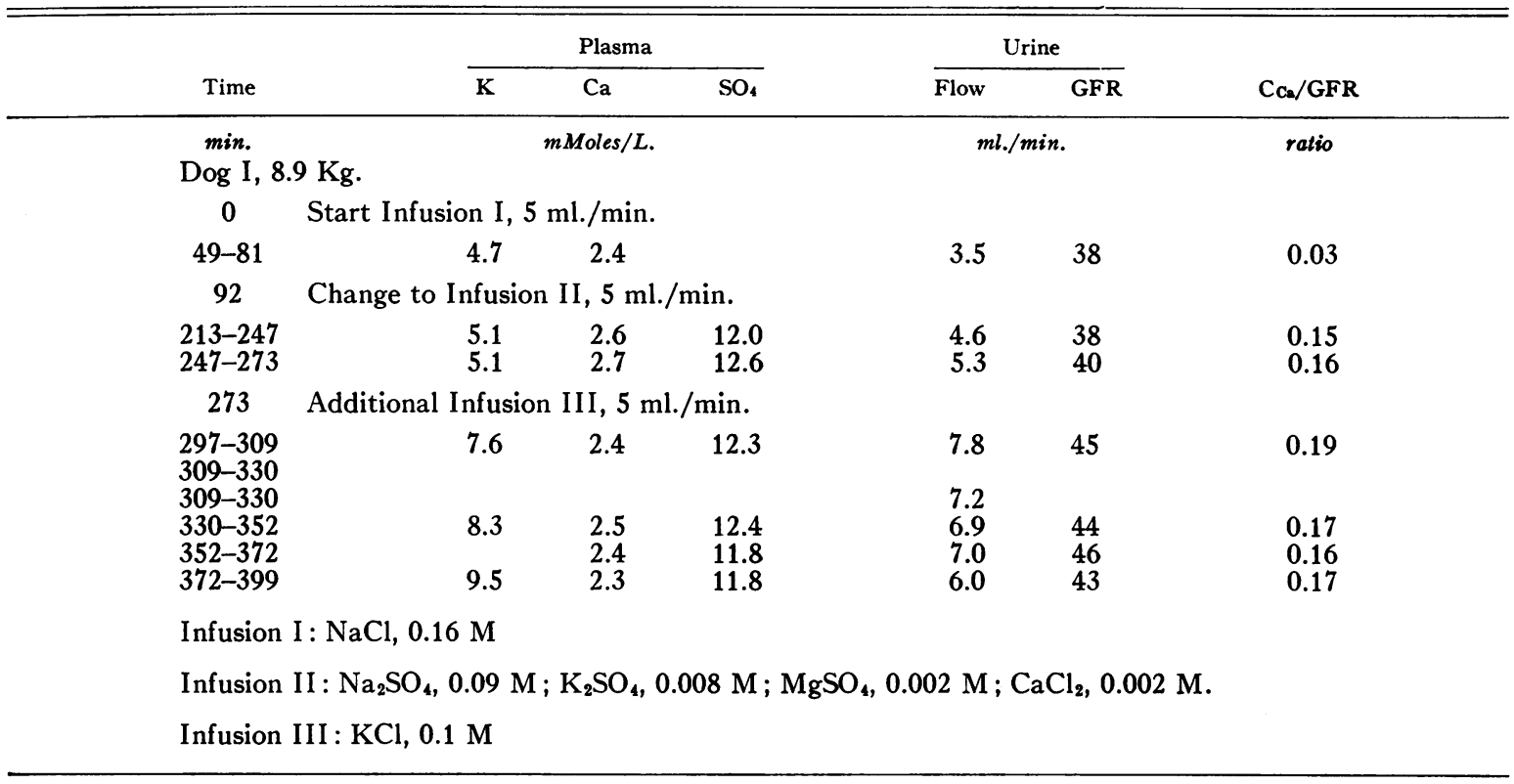

sium balance. In some instances this resulted in hyperkalemia. Three experiments were therefore conducted to determine whether excess potassium modifies the relationship depicted in Figure 1 . The results in one experiment are presented in Table II. The infusion of $\mathrm{KCl}$ in amounts sufficient to increase plasma potassium concentration to $9 \mathrm{mEq}$. per L. did not alter calcium excretion appreciably. The results in the other two experiments were similar.

\section{The role of filtration rate}

The administration of $\mathrm{NaCl}$ or $\mathrm{NaHCO}_{3}$ usually led to a rise in filtration rate. In the sulfate experiments, glomerular filtration rate usually remained within normal limits. In the six experiments in which peritoneal dialysis was performed to achieve higher plasma sulfate concentrations, filtration rate eventually fell to subnormal levels, but these data have not been included. The mean normal filtration rate in dogs is reported to be $4.3 \mathrm{ml}$. per minute per $\mathrm{Kg}$. (24). The range of filtration rates observed in the sulfate experiments shown in Figure 1 was 3 to $7 \mathrm{ml}$. per minute per $\mathrm{Kg}$. In this range, the calcium clearance ratio was not appreciably affected by variations in filtration rate.
The relationship between calcium excretion and sulfate excretion

In approximately half of the collection periods depicted in Figure 1, plasma and urine were analyzed for sulfate in order to define the relationship between calcium and sulfate excretion. There are a number of ways of expressing the results, $e . g$., calcium excretion (or clearance) as a function of the sulfate level of plasma or the excretion of sulfate. Each of these yields a more or less

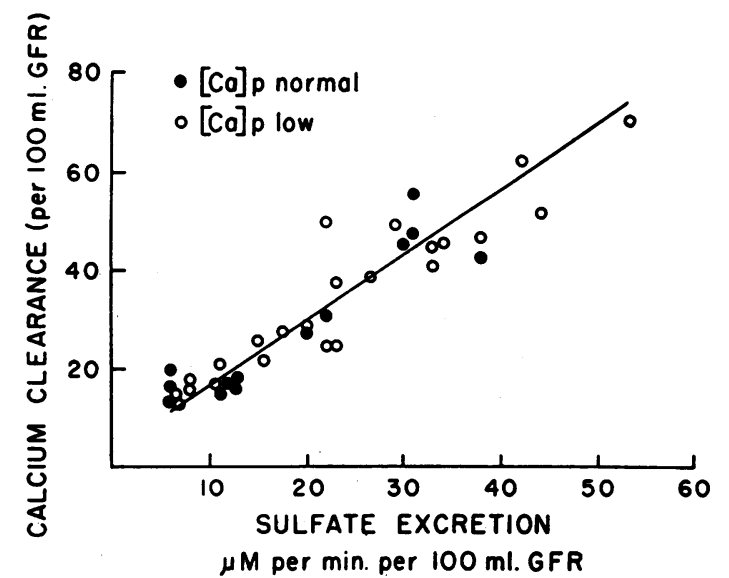

Fig. 2. Calcium Clearance as a Function of Sulfate Excretion During Sulfate Diuresis 
linear relationship. The most useful appears to be that depicted in Figure 2, i.e., calcium clearance as a function of sulfate excretion, both parameters having been corrected to $100 \mathrm{ml}$. of glomerular filtration rate. The straight line indicates that the ratio of calcium concentration in urine to that in plasma is proportional to the urine sulfate concentration. During sulfate diuresis, the urinary concentration of sulfate varied from 60 to 140 mMoles per L. but was unrelated to the rate of sulfate administration. The data indicate that each millimole of sulfate excreted is accompanied by $0.03 \mathrm{mMole}$ of calcium, provided plasma calcium is normal, and correspondingly less during hypocalcemia.

\section{Other effects of sulfate infusion}

Sulfate appeared to be completely nontoxic to animals in whom deficiencies of calcium, magnesium and potassium were prevented by the addition of these cations to the infusions. In one animal weighing $17.9 \mathrm{Kg}$., a continuous intravenous infusion was maintained for four days during which $34 \mathrm{~L}$. of distilled water was given, containing $435 \mathrm{Gm}$. $\mathrm{Na}_{2} \mathrm{SO}_{4}, 44 \mathrm{Gm} . \mathrm{K}_{2} \mathrm{SO}_{4}, 10 \mathrm{Gm}$. $\mathrm{CaCl}_{2}$ and $16 \mathrm{Gm}$. $\mathrm{MgSO}_{4}$. No significant change occurred in plasma calcium, magnesium or potassium concentrations or in the glomerular filtration rate; the dog's appetite and disposition were unaffected. The toxicity of sulfate described earlier by us (1) apparently represented magnesium deficiency, since it can be prevented by adding $\mathrm{MgSO}_{4}$ to the infusions.

Measurements of the plasma sodium, potassium and chloride concentrations, osmolality, total $\mathrm{CO}_{2}$ and $\mathrm{pH}$ were also made in most experiments. Usually, plasma sodium rose, chloride and osmolality fell, and potassium, $\mathrm{CO}_{2}$ and $\mathrm{pH}$ remained normal. These data do not appear to have any direct bearing on the relationship under study here, and have therefore been omitted. Urine $\mathrm{pH}$ varied widely, but had no apparent effect on the calcium clearance ratios.

\section{DISCUSSION}

These observations indicate that the infusion of large amounts of sulfate in dogs leads to a marked increase in calcium excretion by the kidney. The urinary concentration of calcium remains higher than that of plasma despite profound diuresis. As a result, sulfate infusion leads to a negative calcium balance and, if given rapidly, to hypocalcemia. On the other hand, the infusion of saline or other osmotic diuretics leads to a fall in urinary calcium concentration and an increment in calcium excretion which is only one-fifth as great.

Since calcium clearance in these experiments was determined without correction for protein binding, it is conceivable that part of the increase in calcium excretion could be attributed to a reduction in the binding of calcium to plasma protein and a consequent increase in the calcium concentration in the glomerular filtrate. Ultrafiltrates were prepared from 32 of these plasma samples by the method of Toribara, Terepka and Dewey (25) and analyzed for calcium. The means (and standard errors) for the diffusible fractions of calcium in normal and sulfate-loaded dogs were $58 \pm 6$ and $75 \pm 2$ per cent, respectively. The average concentration of calcium in glomerular filtrate, relative to that in plasma, is therefore increased by $(75-58) / 58$, or 29 per cent, during sulfate diuresis. However, calcium excretion was increased approximately fivefold during sulfate diuresis, as compared to saline diuresis, and this effect persisted despite marked hypocalcemia. Therefore the changes in calcium excretion cannot be attributed to altered binding of calcium to plasma protein. The significance of this change in protein binding is under study. Plasma protein concentration, determined in four experiments, either remained constant or decreased 10 to 20 per cent, a change far too small to account for the observed increase in the diffusible fraction of calcium.

The possibility that these effects of sulfate may be due to complex formation between calcium and sulfate may now be considered. The association between calcium and sulfate is known to be weak compared to that between calcium and citrate, for example. Dissociation constants at ionic strength $0.16 \mathrm{M}$ are $0.06 \mathrm{M}$ for calcium sulfate and $0.0006 \mathrm{M}$ for the calcium citrate complex [(26), Vol. I, page 39, Vol. II, page 80]. Therefore the question arises whether the electrostatic complex between calcium and sulfate can be present in amounts sufficient to account for the present findings. This question is difficult to answer, since the concentrations of calcium and sulfate, 
as well as the ionic strength of the tubular fluid, change progressively from glomerulus to the final urine However, it is possible to estimate the fraction of urinary calcium electrostatically paired with sulfate. The concentration of sulfate in the urine is approximately $0.10 \mathrm{M}$ during sulfate diuresis even at infusion rates of less than $5 \mathrm{ml}$. per minute. Since no other anion is present in significant concentrations during prolonged infusion of sulfate and since the predominant cations are monovalent, the ionic strength of the urine is approximately 0.3 M. Using a standard activity coefficient equation such as that of Davies [ (6), Equation :9.13, page 230] the dissociation constant of calcium sulfate at this ionic strength becomes approximately $0.08 \mathrm{M}$. The ratio of free calcium ions to calcium complexed by sulfate can therefore be calculated as $0.08 / 0.10$ or 0.8 .

Thus approximately half of the calcium in the urine is electrostatically associated with sulfate.

There are no comparable observations to indicate what fraction of the urinary calcium is complexed by citrate or EDTA during infusion of these agents. It would be of interest to determine how the clearance of free calcium ions varies during administration of these substances as compared to sulfate. At present it can only be stated that the association of sulfate with calcium is the most likely explanation of its effect on calcium excretion, just as the complexing of calcium by citrate and EDTA is their probable mechanism of action. Each agent is effective at a concentration which reflects its affinity for calcium: EDTA in minute amounts, citrate in intermediate quantities, and sulfate in relatively large quantities. Sulfate is somewhat easier to employ for this purpose because the risk of tetany is less than with EDTA, and unlike citrate, it is not metabolized (27).

Apart from these considerations, the principal significance of this study lies in the demonstration that electrostatic complexes may affect renal excretion of ions. It is customary to consider the renal transport of individual ions as separate processes, in which the requirement of electroneutrality is fulfilled either by exchange with particles of like charge or by secondary movements of oppositely charged ions. The present studies indicate that, in addition, tubular transport may be modified by electrostatic interaction between ions of opposite charge. Thus metals cannot be con- sidered as free, physiologically speaking, even though they are fully ionized. The calcium electrostatically paired with sulfate is believed to be ionized but yet undissociated. Its tubular reabsorption is apparently impaired. Other aspects of this phenomenon have been discussed elsewhere $(7,8)$.

\section{SUM M.ARY}

Intravenous infusion of sulfate in dogs leads to a marked increase in calcium excretion. Calcium clearance in relation to filtration rate was on the average five times greater than during comparable diuresis induced by $\mathrm{NaCl}, \mathrm{NaHCO}_{3}$ or sucrose. Rapid sulfate infusion led to hypocalcemia; nevertheless, hypercalcuria persisted. The data have been analyzed in terms of electrostatic association between calcium and sulfate ions in the renal tubular fluid. Half of the urinary calcium was estimated to be paired with sulfate ions. It is concluded that ion-pair formation may play a role in the renal transport of certain electrolytes.

\section{ACKNOWLEDGMENTS}

We are indebted to Dr. Gilbert H. Mudge and Dr. Irwin $M$. Weiner for many helpful suggestions, and to Sylvia E. Butler for technical assistance.

\section{REFERENCES}

1. Walser, M., and Browder, A. Studies on the replacements of body chloride by sulfate. J. Pharm. exp. Ther. 1958, 122, 81A.

2. Walser, M., and Browder, A. A. Excretion of divalent cations during sulfate diuresis. Fed. Proc. 1958, 17, 168.

3. Chang, T. S., and Freeman, S. Citric acid and its relation to serum and urinary calcium. Amer. J. Physiol. 1950, 160, 330.

4. Holland, J. F., Danielson, E., and Sahagian-Edwards, A. Use of ethylene diamine tetraacetic acid in hypercalcemic patients. Proc. Soc. exp. Biol. (N. Y.) 1953, 84, 359.

5. Interaction in ionic solutions. Disc. Faraday Soc. 1957, No. 24, 1-239.

6. Robinson, R. A., and Stokes, R. H. Electrolyte Solutions. London, Butterworth Scientific Publications, 1955.

7. Walser, M. Ion association. I. The effect of multivalent anions on the concentration of free calcium ions in serum ultrafiltrate. Submitted for publication.

8. Payne, J. W., and Walser, M. The effect of multivalent anions on the concentration of free calcium ions as measured by the frog heart method. Fed. Proc. 1959, 18, 118. 
9. Wolf, A. V., and Ball, S. M. Effect of intravenous sodium sulfate on renal excretion in the dog. Amer. J. Physiol. 1950, 160, 353.

10. Whittlesey, P. A continuous intravenous infusion apparatus for the unanesthetized dog. J. Lab. clin. Med. 1954, 43, 324.

11. Chesley, L. C., and Tepper, I. Some effects of magnesium loading upon renal excretion of magnesium and certain other electrolytes. J. clin. Invest. 1958, 37, 1362.

12. Kramer, B., and Tisdall, F. F. A simple technique for the determination of calcium and magnesium in small amounts of serum. J. biol. Chem. 1921, 47, 475.

13. Clark, E. P., and Collip, J. B. A study of the Tisdall method for the determination of blood serum calcium with a suggested modification. J. biol. Chem. 1925, 63, 461 .

14. Orange, M., and Rhein, H. C. Microestimation of magnesium in body fluids. J. biol. Chem. 1951, 189, 379.

15. Glick, D., Freier, E. F., and Ochs, M. J. Studies in histochemistry. XLVII. Microdetermination of magnesium and its histological distribution in the adrenal in various functional states. J. biol. Chem. 1957, 226, 77.

16. Cotlove, E., Trantham, H. V., and Bowman, R. L. An instrument and method for automatic, rapid, accurate, and sensitive titration of chloride in biologic samples. J. Lab. clin. Med. 1958, 51, 461.

17. Power, M. H., and Wakefield, E. G. A volumetric method for the determination of inorganic and ethereal sulfate in serum. J. biol. Chem. 1938, 123,665 .

18. Letonoff, T. V., and Reinhold, J. G. A colorimetric method for the determination of inorganic sulfate in serum and urine. J. biol. Chem. 1936, 114, 147.
19. Kleeman, C. R., Taborsky, E., and Epstein, F. H. Improved method for determination of inorganic sulfate in biologic fluids. Proc. Soc. exp. Biol. (N. Y.) 1956, 91, 480.

20. Kennedy, T. J., Jr., Hilton, J. G., and Berliner, R. W. Comparison of inulin and creatinine clearance in the normal dog. Amer. J. Physiol. 1952, 171, 164.

21. Wolfson, W. Q., Cohn, C., Calvary, E., and Ichiba, F. Studies in serum proteins. V. A rapid procedure for the estimation of total protein, true albumin, total globulin, alpha globulin, beta globulin, and gamma globulin in $1.0 \mathrm{ml}$. of serum. Amer. J. clin. Path. 1948, 18, 723.

22. Chen, P. S., Jr., and Neuman, W. F. Renal excretion of calcium by the dog. Amer. J. Physiol. $1955,180,623$.

23. Freeman, S., Jacobsen, A. B., and Williamson, B. J. Acid-base balance and removal of injected calcium from the circulation. Amer. J. Physiol. 1957, $191,377$.

24. Houck, C. R. Statistical analysis of filtration rate and effective renal plasma flow related to weight and surface area in dogs. Amer. J. Physiol. 1948, 153, 169.

25. Toribara, T. Y., Terepka, A. R., and Dewey, P. A. The ultrafiltrable calcium of human serum. I. Ultrafiltration methods and normal values. J. clin. Invest. 1957, 36, 738.

26. Bjerrum, J., Schwarzenbach, G., and Sillen, L. G. Stability constants. Part I: Organic ligands; Part II: Inorganic ligands, Special Publ. No. 6 and No. 7, Chem. Soc. (London), 1957.

27. Walser, M., Reid, A. F., and Seldin, D. W. A method of counting radiosulfur in liquid samples and its application to the determination of $\mathrm{S}^{35} \mathrm{O}_{4}$. Arch. Biochem. 1953, 45, 91. 